\title{
Monitoring of noncommunicable diseases
}

\author{
Sandeep Kumar, Vivek Aggarwal, K. V. S. Hari Kumar ${ }^{1}$ \\ Department of Medicine, AFMC, Pune, Maharashtra, ${ }^{1}$ Department of Endocrinology, Command Hospital, Chandimandir, Panchkula, Haryana, \\ India
}

\section{A B S T R A C T}

Noncommunicable diseases (NCDs) represent a major fraction of the global health burden in terms of morbidity and mortality, and its prevalence is on the rise across the world. As more and more people are living with various NCD, primary and secondary prevention becomes an important tool to contain this impending epidemic. The spectrum of major NCD includes cardiovascular disorders (CVD), diabetes mellitus (DM), chronic obstructive pulmonary disorder (COPD), and cancer, with CVD contributing to the majority of deaths attributed to NCD. Control of hypertension is important intervention which can significantly decrease the risk of CVD, which can be achieved by three-pronged approaches such as encompassing dietary, physical exercise, and pharmacological interventions. Monitoring is an integral part of this approach, wherein recording of blood pressure and various investigations are required to be done at variable intervals. DM is an important NCD where primary and secondary preventions are of paramount importance. Similarly, other NCDs such as COPD and cancer also require various monitoring protocols. In this article, we review the current concepts in monitoring and prevention of major NCDs along with the recommendations from the scientific societies.

Key words: Cardiovascular disorders, diabetes, monitoring, noncommunicable diseases, screening

\section{INTRODUCTION}

Noncommunicable diseases (NCDs) represent a major fraction of the global health burden and are responsible for over 38 million deaths each year. ${ }^{[1]}$ The spectrum of major NCD includes cardiovascular disorders (CVD), diabetes mellitus (DM), chronic obstructive pulmonary disorder (COPD), and cancer. CVD leads the pack with about 18 million deaths annually, followed by cancer (8 million), COPD (4 million), and DM (1.5 million). The World Health Organization estimates suggest that one in every seven human beings would have one of these diseases at some point in their lifespan. Commonly held belief of NCD being a chronic disease with little clinical significance are refuted, through rapidly evolving and sometimes fatal NCD such as autoimmune conditions,

\begin{tabular}{|l|l|}
\hline \multicolumn{2}{|c|}{ Access this article online } \\
\hline Quick Response Code: & Website: \\
\hline & www.joshd.net \\
\hline & \\
\hline & \\
\hline
\end{tabular}

malignancies, and CVD. The concept of NCD being more prevalent in developed nations is no longer true, with a staggering two-thirds of NCD mortality being reported from the resource-limited countries. The NCD is both heritable and acquired; their management is enigmatic, and there is no sustainable cure for them. In this article, we review the current concepts in monitoring and prevention of major NCD.

\section{CARDIOVASCULAR DISORDERS}

Hypertension (HTN), coronary artery disease (CAD), cerebrovascular accident (CVA), and peripheral

\begin{abstract}
This is an open access article distributed under the terms of the Creative Commons Attribution-NonCommercial-ShareAlike 3.0 License, which allows others to remix, tweak, and build upon the work non-commercially, as long as the author is credited and the new creations are licensed under the identical terms.
\end{abstract}

For reprints contact: reprints@medknow.com

How to cite this article: Kumar S, Aggarwal V, Kumar KH. Monitoring of noncommunicable diseases. J Soc Health Diabetes 2016;4:85-9.

Corresponding Author: Dr. K. V. S. Hari Kumar, Department of Endocrinology, Command Hospital, Chandimandir, Panchkula, Haryana, India. E-mail: hariendo@rediffmail.com 
arterial disease accounts for $15 \%$ of the 92 million disability-adjusted life years worldwide, thereby demonstrating its significance in global disease burden. ${ }^{[2]}$ HTN is the proverbial silent killer, which doubles the risk of CVD including heart failure, CAD, and CVA. The environmental and genetic factors contribute to regional and racial variations in HTN prevalence. Psychosocial stress, sedentary lifestyle, and alcohol consumption may contribute to the development of HTN. Evidence suggests that $15-35 \%$ of HTN is heritable, which is even higher in twins up to $60 \%$. Furthermore, HTN occurs 3.8 times more commonly in males above the of age 55 years with a positive family history of the disease. ${ }^{[2]}$ While there is ample evidence to demonstrate heritability, a small fraction of this heritability is linked to specific genetic determinants. Therefore, both primary and secondary preventions play a pivotal role in prevention and control of this disease. ${ }^{[3,4]}$

The effective control of HTN involves certain dietary and lifestyle modifications, which have been effective at an individual and societal level. ${ }^{[5,6]}$ Earlier studies pertaining to individual nutrients and micronutrients have now paved the way for dietary patterns as a whole, rather than focusing on the individual constituents. Two major dietary interventions exist for HTN, Mediterranean diet, and dietary approaches to stop HTN diet as shown in Table 1 . The primary and secondary prevention of HTN is also based on certain lifestyle changes which include restricting sodium and potassium intake, cessation of smoking, and aerobic exercise as shown in Box $1^{[5-8]}$ The follow-up visits after a diagnosis of HTN, CAD, or CVA are not strictly scheduled. Guidelines from the major scientific societies suggest a customized approach depending on the individual patient and the underlying clinical condition. ${ }^{[9]}$ The monitoring of a patient with HTN is described in Box 2.

\section{CANCER}

Improved understanding of pathogenesis and progression has allowed for earlier detection and treatment of various cancers. The goal of cancer treatment is to prevent morbidity and mortality through early detection and effective management. The early identification of cancer involves certain screening procedures as summarized in Table $2 .{ }^{[10]}$ The management of malignancy is a complex process which requires constant monitoring of patients being treated with chemotherapy or radiotherapy. The patient should be monitored for response to treatment, development of complications, and recurrence of cancer. Various oncological emergencies during the

\section{Table 1: Dietary approaches to stop hypertension}

Mediterranean pattern

A diet higher in fresh fruits, vegetables (root and green varieties) cereals, and fish containing PUFA. This diet is low in nondiary fat and consists of oils like olive oil and canola. The Mediterranean diet tends to be higher in unsaturated fat (35\% of total calories) and dietary (25 g/day)

DASH pattern

The DASH dietary pattern is high in vegetables, fruits, low-fat dairy, products, whole grains, poultry, fish, and nuts and low in sweets, sugar-sweetened beverages, and red meats; low in saturated fat, total fat, and cholesterol; and rich in potassium, magnesium, and calcium, as well as in protein and fiber

PUFA: Polyunsaturated fatty acids; DASH: Dietary approaches to stop hypertension

\section{Box 1: Lifestyle measures to prevent hypertension}

Restrict sodium intake to below $2.3 \mathrm{~g} /$ day

Adequate potassium intake of $>4.7 \mathrm{~g} /$ day

Reduce the carbohydrate content to $<55 \%$ of total calories

Reduced consumption of sugar-sweetened beverages

Avoid alcohol consumption and smoking

Daily physical activity

Maintain the ideal body weight

\section{Box 2: Monitoring of a hypertensive patient \\ Blood pressure measurement during every office visit or monthly intervals \\ Modify the antihypertensive drugs at 3 monthly intervals if required Biochemistry panel, electrocardiography, fundus examination every year \\ Renal function tests and electrolytes every 3 monthly in patients on renin-angiotensin-aldosterone system blockers}

treatment form an important hurdle to continue further management of the patient. Oncological emergencies range from dyselectrolytemia to life-threatening conditions such as anaphylaxis, acute airway obstruction, pericardial tamponade, and spinal cord compression. Early intervention during these oncological emergencies reduces the mortality and morbidity. Neoplasms of the lung, breast and bone, leukemia, and lymphomas are the common malignancies that lead to systemic complications. Figure 1 describes the systemic complications that require constant monitoring during the management of patients with cancer.

\section{ChRONIC OBSTRUCTIVE PULMONARY DISORDER}

Slow evolution and progressive nature present various avenues for the prevention of chronic respiratory diseases. However, a long-term and systematic approach is required for their effective prevention. Asthma, bronchiectasis, COPD, chronic rhinosinusitis, hypersensitivity pneumonitis, and lung fibrosis represent most of these illnesses. Smoking and consumption of tobacco are the major culprits behind 


\begin{tabular}{|c|c|c|}
\hline $\begin{array}{l}\text { Cancer } \\
\text { type }\end{array}$ & Test or procedure & Screening recommendations* \\
\hline \multirow[t]{2}{*}{ Cervical } & Pap smear & $\begin{array}{l}\text { Women } 21-64 \text { years - every } 3 \text { years } \\
\text { No screening for women for }>65 \text { years, if adequate prior screenings }\end{array}$ \\
\hline & HPV test & Women $30-65$ years every 5 years \\
\hline \multirow[t]{5}{*}{ Colorectal } & Sigmoidoscopy & Adults $50-75$ years every 5 years with annual high-sensitivity fecal occult blood testing \\
\hline & Colonoscopy & Adults $50-65$ years every 10 years \\
\hline & Fecal DNA testing & Adults $>50$ years every 5 years \\
\hline & Fecal immunochemical testing & Adults $>50$ years every year \\
\hline & CT colonography & Adults $>50$ years, every 5 years \\
\hline Lung & Low-dose CT & $\begin{array}{l}\text { Adults } 55-80 \text { years with a }>30 \text { pack year smoking history, still smoking or having quit } \\
15 \text { years ago }\end{array}$ \\
\hline Ovary & CA-125 TV USG & $\begin{array}{l}\text { For women with persistent symptoms suggestive of CA ovary, a combination of CA-125 } \\
\text { and TV USG may be done }\end{array}$ \\
\hline Prostate & PSA & Men $>50$ years, frequency to be guided by PSA levels \\
\hline Skin & Self-examination & Monthly \\
\hline \multirow[t]{4}{*}{ Breast } & Self-examination & All ages \\
\hline & Clinical exam & $\begin{array}{l}\text { Women } 20-39 \text { years - every } 3 \text { years } \\
\text { Women }>40 \text { years - annually }\end{array}$ \\
\hline & Mammography & Women $>40$ years annually \\
\hline & MRI & Women $>20 \%$ lifetime risk, combine with annual mammography \\
\hline
\end{tabular}

*The American Cancer Society and the US Preventive Services Task Force Guidelines for Screening. HPV: Human papillomavirus; CT: Computed tomography; CA: Cancer antigen; TV: Transvaginal; USG: Ultrasonography; PSA: Prostate specific antigen; MRI: Magnetic resonance imaging

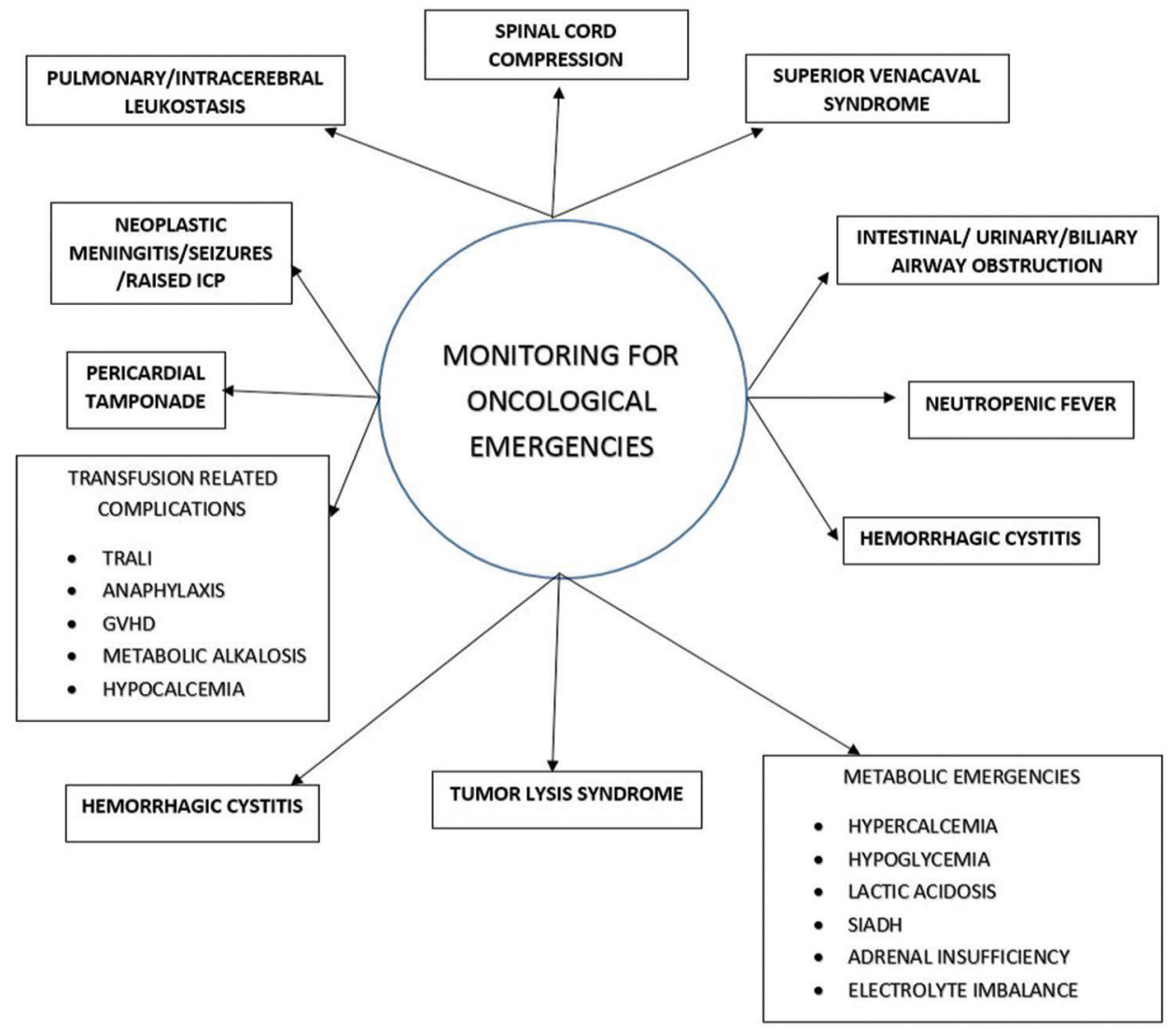

Figure 1: Monitoring for complications in cancer

the rise in the prevalence of the COPD. Table 3 gives the measures to be adopted at the community level to prevent the menace of the smoking. ${ }^{[11]}$ The only intervention which has shown benefit in preventing the progressive deterioration in lung function among COPD patients is cessation of smoking. Monitoring smoking cessation and reemphasizing the need to quit may be beneficial for both short- and long-term. ${ }^{[1]}$ 
COPD is a chronic progressive disease with varying course and high morbidity, and the need for effective monitoring has been emphasized by most of the treatment guidelines. The frequency of visit should be individualized and determined by the clinical status of the patient. ${ }^{[12]}$ The GOLD has classified patients into groups according to symptoms and risk; accordingly, monitoring should also assess these two by history taking and spirometry to assess airflow limitation. ${ }^{[13]}$ Symptom identification and early intervention in exacerbations should be included in monitoring to avoid hospital admissions and to increase the quality of life. ${ }^{[14]}$ Medications usage, correct technique of inhaler administration, and the possible side effects should be reviewed during every visit, and patient educational sessions may be added to the routine. The monitoring should also be aimed at identifying comorbidities which are more associated with COPD such as cardiac failure, osteoporosis, and bronchiectasis so as to initiate treatment at the early stage. Patients should be vaccinated against pneumococcus and influenza to prevent the recurrent exacerbations. ${ }^{[13]}$

\section{Diabetes Mellitus}

The sine-qua-non among all NCD is DM, which affects 420 million persons worldwide. The disease claims a life every $11 \mathrm{~s}$ and the annual health expenditure is close to 673 billion USD, reflecting 12\% of the global health expenditure. ${ }^{[15]}$ Type 2 DM screening should be carried out in adults of who are overweight or obese, and who have one or more diabetes risk factors using A1C, fasting plasma glucose, or $2 \mathrm{~h} \mathrm{PG}$ after $75 \mathrm{~g}$ oral glucose tolerance test criteria. If the initial test is normal,

\section{Table 3: Measures to reduce the community burden of}

\section{tobacco use}

Reduce affordability of tobacco products by increasing tobacco excise taxes

Create by law completely smoke-free environments in all indoor workplaces, public places, and public transport

Warn people of the dangers of tobacco and tobacco smoke through effective health warnings and mass media campaigns

Ban all forms of tobacco advertising, promotion, and sponsorship it should be repeated every 3 years. On the other hand, screening for Type $1 \mathrm{DM}$ is usually done in the setting of a clinical research study and blood glucose is preferred over $\mathrm{A} 1 \mathrm{C}$ to diagnose the acute onset of Type $1 \mathrm{DM}$ with symptoms of hyperglycemia. ${ }^{[16]}$ The International Diabetes Federation has issued guidelines for the "recommended care" category, as well as for the "limited care" in the resource limited locations. The goals of therapy, however, remain the same, regardless of the setting. These include control of hyperglycemia and prevention of microvascular and macrovascular complications, thereby facilitating a normal life for the patient. ${ }^{[17]}$

The cornerstone of management in DM is lifestyle modification along with pharmacological therapies. However, comprehensive diabetes care consists of a multidisciplinary team that includes a diabetologist, nutritionist, podiatrist, and psychologist. Additional members include other specialists such as neurologists, nephrologists, vascular surgeons, cardiologists, ophthalmologists, gastroenterologists, and surgical specialists. A major fraction of the mortality and morbidity secondary to diabetes can be prevented using certain stringent surveillance measures. For example, The American Diabetes Association recommends initial eye examination within 5 years for Type 1 diabetes and at the time of diagnosis for Type 2 diabetes as shown in Figure 2. Self-monitoring of blood glucose (SMBG) is the preferred method for individuals receiving multiple dose insulin or insulin pump therapy. It is usually done before meals, at bedtime, prior to exercise, when hypoglycemia is suspected, and before high-risk activities such as driving. Continuous glucose monitoring is a useful supplement to SMBG in patients with intensive insulin therapy or hypoglycemic unawareness. ${ }^{[16]}$

Management of DM involves screening for associated comorbidities and complications at regular intervals. HTN screening requires measurement of blood pressure at every visit. Lipid profile needs to be checked initially at the time of diagnosis and every 5 years thereafter. Consider investigating for $\mathrm{CAD}$ in the presence of suggestive clinical

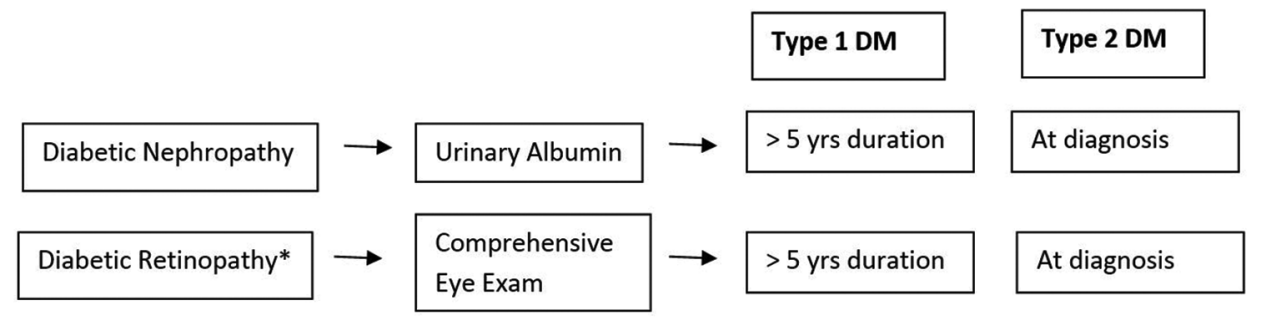

Figure 2: Monitoring for microvascular disease in diabetes mellitus 
features of vascular disease, including carotid bruits, absent pulses, and electrocardiography abnormalities. In addition to the above annual foot exam to identify risk factors, predictive of ulcers and amputations have been recommended. Screening for autoimmune diseases in children and adolescents with Type 1 diabetes has also been recommended. Screening for celiac disease soon after Type 1 diabetes diagnosis by measuring tissue transglutaminase or deamidated gliadin antibodies, with documentation of normal total serum IgA levels is done. All patients with Type $1 \mathrm{DM}$ should be screened for autoimmune thyroiditis by measuring thyroid peroxidase antibodies. ${ }^{[18]}$

\section{CONCLUSION}

The burden of NCDs is increasing rapidly, and effective measures are required at various levels to combat this epidemic. CVD and DM affect a majority followed closely by cancer and COPD. Regular monitoring and effective screening strategies are essential to identify them early in the course and institute corrective measures. Patient education and awareness are also important objectives in combating the epidemic.

\section{Financial support and sponsorship}

Nil.

\section{Conflicts of interest}

There are no conflicts of interest.

\section{REFERENCES}

1. Lim SS, Vos T, Flaxman AD, Danaei G, Shibuya K, Adair-Rohani H, et al. A comparative risk assessment of burden of disease and injury attributable to 67 risk factors and risk factor clusters in 21 regions, 1990-2010: A systematic analysis for the Global Burden of Disease Study 2010. Lancet 2012;380:2224-60.

2. Kasper DL, Fauci AS, Hauser SL, Longo DL, Jameson JL, Loscaizo J. Harrison's principles of internal medicine. $19^{\text {th }}$ ed: New York: McGraw Hill Education 2015. p. 298,1612-24.

3. Huber-Geismann F. Primary prevention in mild hypertension. Praxis (Bern 1994) 2013;102:55.

4. Sheridan S, Pignone M. Primary prevention: Hypertension. Clin Evid 2005;14:151-9.
5. Ravenni R, Jabre JF, Casiglia E, Mazza A. Primary stroke prevention and hypertension treatment: Which is the first-line strategy? Neurol Int 2011;3:e12.

6. Sheridan S. Primary prevention of CVD: Treating hypertension. BMJ Clin Evid 2007;2007. pii: 0214.

7. Klonizakis M, Alkhatib A, Middleton G, Smith MF. Mediterranean diet- and exercise-induced improvement in age-dependent vascular activity. Clin Sci (Lond) 2013;124:579-87.

8. Kwan MW, Wong MC, Wang HH, Liu KQ, Lee CL, Yan BP, et al. Compliance with the Dietary Approaches to Stop Hypertension (DASH) diet: A systematic review. PLoS One 2013;8:e78412.

9. Joel Handler MJ. Essential Hypertension, UK: The BMJ Group; 2016. Available from: http://www.bestpractice.bmj.com/ best-practice/monograph/26/follow-up/recommendations.html. [Last updated on 2016 Feb 03; Last cited on 2016 Jun 29].

10. American Cancer Society Guidelines for the Early Detection of Cancer. American Cancer Society, Inc., No. 207000 Rev. 9/15. Available from: http://www.cancer.org/acs/groups/content/@ editorial/documents/document/acspc-046343.pdf. [Last accessed on $2016 \mathrm{Jul} 22$ ].

11. Qaseem A, Wilt TJ, Weinberger SE, Hanania NA, Criner G, van der Molen T, et al. Diagnosis and management of stable chronic obstructive pulmonary disease: A clinical practice guideline update from the American College of Physicians, American College of Chest Physicians, American Thoracic Society, and European Respiratory Society. Ann Intern Med 2011;155:179-91.

12. van den Bemt $L$, Schermer T, Smeele I, Bischoff E, Jacobs A, Grol R, et al. Monitoring of patients with COPD: A review of current guidelines' recommendations. Respir Med 2008;102:633-41.

13. Vestbo J, Hurd SS, Agustí AG, Jones PW, Vogelmeier C, Anzueto A, et al. Global strategy for the diagnosis, management, and prevention of chronic obstructive pulmonary disease: GOLD executive summary. Am J Respir Crit Care Med 2013;187:347-65.

14. Wagena EJ, van der Meer RM, Ostelo RJ, Jacobs JE, van Schayck CP. The efficacy of smoking cessation strategies in people with chronic obstructive pulmonary disease: Results from a systematic review. Respir Med 2004;98:805-15.

15. International Diabetes Federation. IDF Diabetes Atlas. $6^{\text {th }}$ ed. Brussels, Belgium: International Diabetes Federation; 2013.

16. 2016 American Diabetes Association (ADA) Diabetes guidelines summary and recommendation from ADEl http://www.ndei.org/ ADA-diabetes-management-guidelines-diagnosis-A1C-testing. aspx.html. [Last accesed on 2016 Jul 04].

17. International Diabetes Federation, 2012. Global Guidelines for Type 2 Diabetes. Available from: https://www.idf.org/sites/ default/files/IDF\%20T2DM\%20Guideline.pdf. [Last accessed on 2016 Jul 20].

18. Kurien M, Mollazadegan K, Sanders DS, Ludvigsson JF. Celiac disease increases risk of thyroid disease in patients with type 1 diabetes: A Nationwide cohort study. Diabetes Care 2016;39:371-5. 